\title{
A PROFICIÊNCIA EM LEITURA NO CICLO DA ALFABETIZAÇÃO EM MATO GROSSO
}

\author{
LA PROFICIENCIA EN LECTURA EN EL CICLO DE LA ALFABETIZACIÓN EN \\ MATO GROSSO
}

THE PROFICIENCY IN READING OF CYCLE OF LITERACY IN MATO GROSSO

Ângela Rita Christofolo de MELLO ${ }^{1}$

RESUMO: O artigo socializa dados parciais da pesquisa realizada com o objetivo de analisar o resultado das avaliações dos estudantes matriculados no último ano do ciclo da alfabetização em Mato Grosso, divulgadas em 2014. A pesquisa de abordagem qualitativa se valeu de levantamentos documentais realizados no site do Instituto Nacional de Estudos e Pesquisas Anísio Teixeira (Inep), Avaliação Nacional da Alfabetização (ANA), bem como das informações alocadas no Sistema Integrado de Monitoramento Execução e Controle do Ministério da Educação (SIMEC), Sistema de Monitoramento para o Curso de Formação para os Orientadores de Estudo vinculados ao Pacto Nacional pela Alfabetização na Idade Certa (SisPacto). Os resultados das avaliações externas e internas foram sistematizados por equivalências entre os níveis de aprendizagem estabelecidos na segunda edição da ANA e os direitos de aprendizagem alocados no SIMEC/SisPacto.

PALAVRAS-CHAVE: Alfabetização. Leitura. Avaliações. Mato Grosso.

RESUMEN: El artículo socializa datos parciales de la investigación realizada con el objetivo de analizar el resultado de las evaluaciones de los estudiantes matriculados en el último año del ciclo de la alfabetización en Mato Grosso, divulgadas en 2014. La investigación de abordaje cualitativo se valió de encuestas documentales realizadas en el sitio del Instituto Nacional de Estudios e Investigaciones Anísio Teixeira (Inep), Evaluación Nacional de la Alfabetización (ANA), sí como de las informaciones asignadas en el Sistema Integrado de Monitoreo Ejecución y Control del Ministerio de Educación (SIMEC), Sistema de Monitoreo para el Curso de Formación para los Orientadores de Estudio vinculados al Pacto Nacional por la Alfabetización en la edad correcta (SisPacto). Los resultados de las evaluaciones externas e internas fueron sistematizados por equivalencias entre los niveles de aprendizaje establecidos en la segunda edición de la ANA y los derechos de aprendizaje asignados en el SIMEC/SisPacto.

PALABRAS CLAVE: Alfabetización. Lectura. Evaluaciones. Mato Grosso.

${ }^{1}$ Universidade do Estado de Mato Grosso (UNEMAT), Juara - MT - Brasil. Professora adjunta credenciada no Profletras. Pós-doutorado do PNPD/PPGEdu/UFMT/CUR, pesquisadora associada à UFMT/CUR e aos Grupos de Pesquisa: ALFALE/UFMT; GRAFITE/UNEMAT e GEFOPE/UNEMAT. Agência de Fomento: CAPES. ORICD <http://orcid.org/0000-0002-9732-6175>. E-mail: angela.mello@unemat.br 
ABSTRACT: he article socializes partial data of the research carried out with the objective of analyzing the results of the evaluations of students enrolled in the last year of the literacy cycle in Mato Grosso, published in 2014. The research of qualitative approach was based on documentary surveys conducted at the National Institute of Studies and Research Anísio Teixeira (Inep), National Literacy Assessment (ANA)., as well as the information allocated in the Integrated System of Monitoring Execution and Control of the Ministry of Education (SIMEC), Monitoring System for the Training Course for Study Advisors linked to the National Pact for Literacy in the right age (SisPacto). The results of the external and internal evaluations were systematized by equivalences between the levels of learning established in the second edition of ANA and the learning rights allocated in SIMEC / SisPacto.

KEYWORDS: Literacy. Reading. Evaluations. Mato Grosso.

\section{Introdução}

Este artigo apresenta dados de uma investigação realizada no âmbito de um estágio de pós-doutoramento, ofertado pelo Programa Nacional de Pós Doutorado (PNPD), por meio da Universidade Federal de Mato Grosso, câmpus de Rondonópolis, Instituto de Ciências Humanas e Sociais, Programa de Pós-graduação em Educação (PPGEdu), linha de pesquisa "Linguagens, Cultura e Construção do Conhecimento: perspectivas histórica e contemporânea", grupo de pesquisa: Alfabetização e Letramento Escolar (ALFALE).

A pesquisa de abordagem qualitativa teve como objetivo analisar os resultados das avaliações dos estudantes matriculados no último ano do ciclo da alfabetização em Mato Grosso, publicizadas no Sistema Integrado de Monitoramento Execução e Controle do Ministério da Educação (SIMEC)/Sistema de Monitoramento para o Curso de Formação para os Orientadores de Estudo vinculados ao Pacto Nacional pela Alfabetização na Idade Certa/(SisPacto) de 2014 e no Instituto Nacional de Estudos e Pesquisas Anísio Teixeira (Inep)/Avaliação Nacional da Alfabetização (ANA) de 2014.

Diante do elevado percentual de estudantes brasileiros que concluíram a Educação Fundamental sem a compreensão leitora e escritora, divulgados pelo Inep nos últimos anos, em 2012, o Ministério da Educação (MEC) institucionalizou o Pacto Nacional Pela Alfabetização na Idade Certa (PNAIC) com o objetivo de alfabetizar todas as crianças nos três primeiros anos da Educação Fundamental. Essa institucionalização demarcou o envolvimento do Distrito Federal, dos Estados e dos municípios brasileiros que pactuaram com os objetivos do MEC (BRASIL, 2012).

As ações do PNAIC foram realizadas pelas Universidades Públicas e Secretarias Estaduais e Municipais de Educação do país. Nesse sentido, em Mato Grosso, a Universidade 
Federal de Mato Grosso, campus Universitário de Rondonópolis (UFMT/CUR), por meio da institucionalização de um projeto de extensão, assumiu a coordenação geral do PNAIC e iniciou as ações de formação dos professores alfabetizadores em janeiro de 2013. Justificamos que o acesso aos resultados das avaliações alocadas no SIMEC/SisPacto pelos professores alfabetizadores vinculados as ações do programa de formação em 2014, foi possível mediante autorização dessa coordenação em abril de 2015, que mantinha o acesso ao sistema resguardado por senha.

\section{SIMEC/SisPacto: monitoramento e controle do Ministério da Educação}

O Sistema Integrado de Monitoramento Execução e Controle do Ministério da Educação (SIMEC) é um portal de gestão do Ministério da Educação (MEC), que trata do orçamento e monitoramento das propostas on-line do governo federal na área da educação. $\mathrm{O}$ Sistema de Monitoramento para o Curso de Formação para os Orientadores de Estudo vinculados ao Pacto Nacional pela Alfabetização na Idade Certa (SisPacto) encontrava-se alocado no SIMEC e sua principal ação era o registro das informações inseridas pelos coordenadores locais, os orientadores de estudo e os professores alfabetizadores. Nesse Sistema, esse público inseriu informações sobre as atividades do PNAIC por eles realizadas, em consonância com a função de cada um.

Para efeito desse processo, a partir da implementação do PNAIC os professores alfabetizadores passaram a inserir as avaliações da aprendizagem de suas turmas no SIMEC/SisPacto. No final de 2013 os alfabetizadores inseriram os resultados das avaliações dos onze direitos de aprendizagem da Língua Portuguesa, alocados por direitos nesse Sistema. Em continuidade às ações do programa, no início e no final do ano de 2014 , os professores alfabetizadores inseriram nesse Sistema os resultados das avaliações da aprendizagem de suas turmas por área de conhecimento, quais sejam: Língua Portuguesa, onze direitos de aprendizagem; Matemática, dezessete direitos de aprendizagem.

Nesse sentido, o SIMEC/SisPacto definiu-se como um sistema de informações criado especialmente para acompanhar e monitorar as ações do PNAIC. Especificamente, em relação à formação continuada dos alfabetizadores, o Sistema informou que em 2013, em Mato Grosso, 5.195 professores alfabetizadores finalizaram as atividades formativas ofertadas pelo PNAIC, de um universo de 5.971 cadastrados no Sistema no início do referido ano. Sendo que 120.489 alfabetizandos estiveram sob a responsabilidade desses professores, que trabalharam com 6.569 turmas (CARDOSO; CARDOSO, 2016). 
Em 2014 de um universo de 5.554 professores inscritos no Sistema no início do ano, 4.289 concluíram as atividades de formação ofertada pelo PNAIC. Foram cadastradas 6.417 turmas no Sistema que atenderam 112.238 alfabetizandos. Desse universo, 33.630 correspondiam aos estudantes matriculados nos $3^{\circ}$ anos que tiveram o resultado de suas avaliações inseridas referido Sistema no final de 2014 (BRASIL, 2015b).

Nesse artigo, analisamos quatro dos direitos de aprendizagem alocados no SIMEC/SisPacto em 2014 equivalentes aos quatro níveis de "leitura" estabelecidos na segunda edição da ANA/2014 pelo Inep.

\section{A Avaliação Nacional da Alfabetização}

A institucionalização da ANA teve como objetivo avaliar o nível de alfabetização dos educandos matriculados no $3^{\circ}$ ano do Ensino Fundamental, a fim de produzir indicadores voltados às condições de oferta da alfabetização com vistas a concorrer com a melhoria da qualidade da educação e reduzir as desigualdades, em consonância às metas e às políticas estabelecidas pelas Diretrizes da Educação Nacional. Alicerçada nesse objetivo, para avaliar os níveis de alfabetização e de letramento das crianças, no final dos anos de 2013 e de 2014 os estudantes matriculados na última etapa do Ciclo de Alfabetização foram submetidos às avaliações da ANA (BRASIL, 2015a).

A avaliação destinada a aferir os estágios de alfabetização das crianças, no último ano desse ciclo, na perspectiva do letramento em Língua Portuguesa conteve dezessete itens objetivos de múltipla escolha e três itens de produção escrita. A ANA avaliou estudantes matriculados no último ano do Ciclo de Alfabetização (BRASIL, 2015a) na edição de 2014, objeto de análise desse artigo.

Como anteriormente afirmamos, segundo os idealizadores da ANA, a sua operacionalização geraria indicadores que contribuiriam com o processo de alfabetização das escolas públicas brasileiras. Para tanto, propunham avaliar o desempenho dos alfabetizandos, bem como as condições de escolaridade destes para desenvolver conhecimentos alfabetizadores. Assim, a estrutura dessa avaliação envolveria o uso de variados instrumentos, cujos objetivos seriam aferir o nível de apropriação do Sistema de Escrita Alfabética e de letramento das crianças regularmente matriculadas no $3^{\circ}$ ano do Ensino Fundamental, bem como as condições de oferta do ciclo da alfabetização das instituições vinculadas ao PNAIC.

Como a ANA seria censitária, aplicar-se-ia, anualmente, a todos os alunos matriculados no $3^{\circ}$ ano do Ensino Fundamental de todas as escolas públicas do Brasil. No 
caso de escolas com turmas multis, apenas uma amostra seria avaliada. Ela utilizaria os instrumentos: questionários contextuais e teste de desempenho. Tanto a sua operacionalização como a sua correção, seriam feitas pelo Inep. Recomendava-se a presença do professor da turma no momento da aplicação da prova.

Em 2015, o MEC/Inep noticiou a suspensão da sua $3^{\text {a }}$ Edição. Segundo o Presidente do Inep, a decisão foi pedagógica e não financeira como inicialmente noticiado ${ }^{2}$. As duas avaliações da ANA aplicadas pelo Inep no final dos anos de 2013 e de 2014 abarcaram doze habilidades de Língua Portuguesa, correspondentes aos eixos estruturantes de leitura e de escrita, sistematizados em quatro níveis de proficiência em leitura e em cinco níveis de proficiência em escrita.

Em relação aos resultados das avaliações realizadas por agentes externos à escola, como a ANA, ressaltamos as críticas que a elas recaem. Segundo Mortatti (2013, p. 29), em relação ao PNAIC, a formação ofertada aos alfabetizadores por meio de políticas de capacitações específicas, enfatiza uma "didática de resultados" e "um ativismo pragmático" porque em sua compreensão, nas formações os alfabetizadores são treinados para aplicar os conteúdos que serão cobrados nas avaliações externas. Essa condição pode desvalorizar a didática enquanto teoria da aprendizagem. Esse "ativismo pragmático", como alerta a autora, impede que os professores alfabetizadores constituam o repertório de conhecimentos conceituais, teórico e metodológicos inerentes aos eventos e práticas de alfabetização na perspectiva dos múltiplos letramentos ${ }^{3}$, posto que esses possam atuar como meros executores de políticas públicas educacionais impostas às escolas e ao seu fazer pedagógico. Para, além disso, as avaliações quantificam estatisticamente o produto sem considerar o processo pelo qual os alfabetizandos se apropriam das vivências que os inserem competentemente nas práticas de alfabetização e letramento crítico.

\section{Compilação, sistematização e análise dos resultados das avaliações dispostas no SIMEC/SisPacto e Inep/ANA/2014}

\footnotetext{
2 Informação disponibilizada em: http://educacao.uol.com.br/noticias/2015a/08/18/governo-federal-suspendeprova-de-alfabetizacao-em-2015a.htm. Acesso em: 28 set. 2015.

${ }^{3} \mathrm{Na}$ compreensão de Rojo (2013), a ação de ler, na perspectiva dos múltiplos letramentos, implica em integrar as diferentes formas de linguagem além da escrita, como a oralidade, a música, os filmes, a imagem (seja esta impressa ou digital), posto que ao realizarmos uma análise reflexiva e contextual sobre as atuais transformações sociais, culturais e tecnológicas, certamente temos de admitir que essas diversificam e suscitam mudanças não somente nas formas e meios de buscar, disponibilizar e compartilhar informações e conhecimentos, mas ainda nas ações de lê-los e elaborá-los. A produção de linguagens híbridas desencadeia, por sua vez, novos desafios aos leitores/escritores e aos profissionais que têm como objeto de trabalho a língua escrita, entre estes, a escola e, neste artigo em especial, os professores alfabetizadores.
} 
A pesquisa realizada fundamentou-se na abordagem qualitativa (MARCONI; LAKATOS, 2002) e se valeu do levantamento documental realizado no SIMEC/SisPacto e no Inep/ANA em 2015. Os resultados das avaliações dos alfabetizandos correspondentes ao ano de 2014 foram sistematizados, compiladas e analisadas por equivalências entre os direitos de aprendizagem em leitura alocados no SIMEC/SisPacto (BRASIL, 2015b) e os quatro níveis de leitura editados no Inep/ANA (BRASIL, 2015a). A justaposição da pesquisadora com o campo de estudo, viabilizou o acesso aos resultados das avaliações. Além disso, as reflexões decorrentes da função de professora formadora do PNAIC em 2014, de professora de metodologia de ensino do curso de pedagogia em que trabalha com as disciplinas de fundamentos teóricos e metodológicos da alfabetização I e II, bem como dos estágios curriculares supervisionados no ciclo da alfabetização, contribuíram com os desdobramentos do processo investigativo, bem como nas reflexões articuladas às análises.

Em 2013, os resultados das avaliações referentes à apropriação dos direitos de aprendizagem de Língua Portuguesa pelas crianças matriculadas nos três anos do Ciclo da Alfabetização nas escolas públicas, foram inseridos no SIMEC/SisPacto apenas no final do ano. A divulgação desses resultados se deu em nível de Brasil, que sistematizou as avaliações de todos os estados da federação. Já em 2014, os resultados das avaliações concernentes aos direitos de aprendizagem de Língua Portuguesa foram inseridos no início e no final do ano letivo pelos professores e os resultados correspondentes ao Estado de Mato Grosso nos foram viabilizados via coordenação do PNAIC desse Estado. Para sistematizá-los, nosso primeiro desafio foi compilar o resultado das avaliações em relação os onze direitos de aprendizagem de Língua Portuguesa por ano de escolarização, dispostos no Sistema no início e no final do ano de 2014, dos estudantes matriculados no Ensino Fundamental de oito anos, no Ensino Fundamental de nove anos e em turmas multis nos três anos do ciclo. Concluída essa primeira etapa da pesquisa, agrupamos por equivalências os direitos de aprendizagem de leitura alocados no Sistema aos níveis de proficiência em leitura editados pelo Inep/ANA/2014. Em seguida, selecionamos o resultado dessas avaliações correspondente aos estudantes matriculados no último ano do ciclo, tendo em vista que a ANA avaliou às crianças matriculadas no $3^{\circ}$ ano da rede pública. Assim, nessa análise por equivalência, nos ativemos aos resultados das avaliações finais dos alfabetizandos do $3^{\circ}$ ano do ciclo dispostas no referido Sistema.

Os fundamentos históricos, legais e conceituais sobre as avaliações realizadas em larga escala e as avaliações internas realizadas no campo da educação publicados nos últimos anos, possibilitaram cientificar as análises dos resultados das referidas avaliações. Dentre os muitos aspectos emblemáticos questionados por esses pesquisadores, destacamos Mortatti (2013, p. 24) 
ao problematizar qual é o conceito de "qualidade da educação e da alfabetização" estabelecido nestas políticas públicas educacionais, que adotam metas, quase sempre definidas por organismos internacionais. "Qualidade para quem? Em relação a que finalidade? A serviço de que ou de quem?". Nesse sentido, a presente análise atentou-se às contradições dessas avaliações, destacadas pelos pesquisadores de políticas públicas educacionais. Dentre esses paradoxos, incluem-se os treinos intensos e as exaustivas repetições didáticas, que tendem impedir intervenções contextualizadas e voltadas à apropriação de conceitos que abarcam todas as áreas do conhecimento e suas respectivas dimensões científicas, sociais, culturais, tecnológicas e humanas. Outro aspecto que, de certa forma, formulou a principal problematização da pesquisa foi: os resultados das avaliações realizadas pelos alfabetizadores inseridos no SIMEC/SisPacto no final de 2014 corresponderam aos resultados decorrentes da edição da ANA de 2014, divulgados pelo Inep em 2015, das respectivas turmas?

\section{A alfabetização em Mato Grosso e os critérios estabelecidos pelo Inep/ANA}

A partir de 2014 o Inep, autarquia vinculada ao Ministério da Educação, passou a publicar o Painel Educacional de cada Estado da federação, com informações consolidadas sobre o cenário educacional dessas Unidades. Essas informações foram organizadas em três abas assim dispostas: 1) Trajetória, que apresenta dados do Censo da Educação Básica coletados pelo Inep; 2) Contexto, que apresenta indicadores educacionais produzidos pelo Inep; 3) Aprendizagem, que apresenta resultados de avaliações realizadas pelo Inep, (BRASIL, 2015a). O referido Painel Educacional apresentou informações das escolas estaduais e municipais de todos os estados que ofertaram os anos iniciais do Ensino Fundamental. Analisamos neste item os dados gerais disponibilizados na aba "Aprendizagem" das escolas estaduais e municipais do Estado de Mato Grosso, correspondentes aos quatro níveis de "leitura".

A ANA tem como objetivo aferir o nível de alfabetização e letramento em Língua Portuguesa, por meio de testes cognitivos. Na edição de 2014, realizada de 17 a 28 de novembro, participaram da avaliação 49.176 escolas públicas de todo o Brasil com aproximadamente 2,5 milhões de estudantes matriculados no $3^{\circ}$ ano do Ensino Fundamental. Deste total, a representação de Mato Grosso encontra-se estruturada no quadro que segue: 
Quadro1 - Escolas de Mato Grosso que participaram da ANA em 2014

\begin{tabular}{|l|l|l|l|}
\hline Escolas/Ano & $\begin{array}{l}\text { Quantidade de escolas } \\
\text { previstas }\end{array}$ & $\begin{array}{l}\text { Quantidade de escolas } \\
\text { participantes }\end{array}$ & $\begin{array}{l}\text { Quantidade de escolas com } \\
\text { resultado divulgado* }\end{array}$ \\
\hline 2014 & 352 & 352 & 303 \\
\hline
\end{tabular}

Fonte: Brasil/Inep/ANA (2015a).

Adaptado pela pesquisadora.

*Em 2014, para atender a uma determinação do Plano Nacional de Educação (PNE), Lei 13.005/2014, tiveram resultados divulgados as escolas que apresentaram taxa igual ou maior a $80 \%$ de participação dos estudantes.

O Inep informou que a previsão e a participação na ANA consideraram as informações declaradas ao Censo da Educação Básica no ano de 2014. Para participar da avaliação, as escolas deveriam ter pelo menos dez estudantes matriculados no $3^{\circ}$ ano do Ensino Fundamental. Os resultados divulgados corresponderam às escolas que tiveram $80 \%$ ou mais dos estudantes matriculados participantes, conforme dados disponibilizados no quadro 2 (Brasil, 2015a).

Quadro 2 - Quantidade de estudantes de Mato Grosso que participaram da ANA em 2014

\begin{tabular}{|l|l|l|l|l|}
\hline Áreas & $\begin{array}{l}\text { Quantidade de alunos } \\
\text { previstos }\end{array}$ & $\begin{array}{l}\text { Quantidade de alunos } \\
\text { presentes }\end{array}$ & $\begin{array}{l}\text { Quantidade de alunos } \\
\text { válidos }\end{array}$ \\
\hline Escrita & 14.905 & 11.936 & 11.815 \\
\hline Leitura & 14.905 & 11.936 & 11.815 \\
\hline Matemática & 14.905 & 12.265 & 12.206 \\
\hline
\end{tabular}

Fonte: Brasil/Inep/ANA (2015a).

Adaptado pela pesquisadora.

Em nota explicativa o Inep informou que a quantidade de estudantes previstos correspondeu ao total de estudantes matriculados nas escolas no $3^{\circ}$ ano do Ensino Fundamental, informado no Censo Escolar de 2014 de Mato Grosso. A quantidade de estudantes presentes indicou o total matriculado nessas escolas, no $3^{\circ}$ ano do Ensino Fundamental, que estavam presentes no dia da realização da ANA. A quantidade de estudantes válidos diz respeito ao total matriculado nas escolas de Mato Grosso, no $3^{\circ}$ ano do Ensino Fundamental, que estavam presentes e que responderam a três ou mais questões objetivas de leitura (BRASIL, 2015a). A leitura destes números indicou que de aproximadamente 33.630 alfabetizandos matriculados no $3^{\circ}$ ano que tiveram suas avaliações inseridas no SIMEC/SisPacto em 2014, em média 12.206 participaram da edição da ANA de $2014^{4}$ em Mato Grosso. Desse modo, o número de alfabetizandos do $3^{\circ}$ ano que obtiveram

${ }^{4}$ O Inep não divulgou os dados gerais dos alunos matriculados no $3^{\circ}$ ano do $1^{\circ}$ ciclo no ano 2013(BRASIL, 2015a). 
suas avaliações inseridas no final de 2014 nesse Sistema foi superior ao número contabilizado na edição da ANA do mesmo ano, conforme quadros que seguem:

Quadro 3 - Quantitativo de estudantes, professores e turmas do $3^{\circ}$ ano do ciclo - dados do SIMEC/SisPacto/2014 de Língua Portuguesa de Mato Grosso

\begin{tabular}{|l|l|}
\hline $\mathrm{N}^{\circ}$ Alunos $3^{\circ}$ Ano (início): 38681 & $\mathrm{~N}^{\circ}$ Alunos $3^{\circ}$ ano (fim): 29653 \\
\hline N. $^{\circ}$ Professores (início): 1637 & N. $^{\circ}$ Professores (fim): 1265 \\
\hline N. $^{\circ}$ Turmas (início): 1777 & N. $^{\circ}$ Turmas (fim): 1350 \\
\hline
\end{tabular}

Fonte: Brasil/MEC/SIMEC/SisPacto (2015b).

Adaptado pela pesquisadora.

Quadro 4 - Quantitativo de estudantes, professores e turmas do $3^{\circ}$ ano do ciclo - dados do SIMEC/SisPacto/2014 de Matemática de Mato Grosso

\begin{tabular}{|l|l|}
\hline $\mathrm{N}^{\circ}$ Alunos $3^{\circ}$ Ano (início): 39153 & $\mathrm{~N}^{\circ}$ Alunos $3^{\circ}$ ano (fim): 33630 \\
\hline N. $^{\circ}$ Professores (início): 1651 & $\mathrm{~N}^{\circ}$ Professores (fim): 1433 \\
\hline N. ${ }^{\circ}$ Turmas (início): 1797 & N. $^{\circ}$ Turmas (fim): 1533 \\
\hline
\end{tabular}

Fonte: Brasil/MEC/SIMEC/SisPacto (2015b).

Adaptado pela pesquisadora.

Destacamos que as turmas multis, tanto do Ensino Fundamental de oito anos, como do Ensino Fundamental de nove anos, não foram incluídas nesses números, portanto a diferença de alfabetizandos que participaram das avaliações, observada entre os números informados pela ANA e pelo SIMEC/SisPacto no ano de 2014, pode ser ainda mais acentuada. A discrepância de 17838 alfabetizandos que tiveram suas avaliações de Língua Portuguesa e de 21424 de Matemática, inseridas nesse Sistema no final de 2014 que não realizaram a ANA, pode se justificar em decorrência dos critérios estabelecidos pelo Inep/ANA (BRASIL, 2015a). Porém, a diferença chamou a nossa atenção e nos fez pensar na possibilidade de que o número de estudantes matriculados no $3^{\circ}$ ano do Ensino Fundamental, nas escolas da rede pública de Mato Grosso, pode não ter correspondido ao quantitativo de alfabetizandos que frequentaram essas turmas. Apesar dessas inconsistências, os números informam que a oferta da alfabetização foi democratizada em Mato Grosso. Todavia, como afirma Mortatti (2013), tal democratização não se justifica porque é um direito de todos os brasileiros e nem porque é dever do estado a sua oferta, mas sim, porque o analfabetismo não pode mais ser empecilho para o avanço do neoliberalismo econômico e político.

Os resultados dos testes de aprendizagem em alfabetização realizados em Mato Grosso nos anos de 2013 e de 2014 estão apresentados em uma Escala de Proficiência. O Inep denomina proficiência como a capacidade para realizar algo, dominar certo assunto e ter aptidão em determinada área do conhecimento. Na Escala de Proficiência, segundo o referido 
Instituto, se agrupam por níveis progressivos e cumulativos as habilidades dos estudantes aferidas nos testes de aprendizagem, da menor para a maior proficiência (BRASIL, 2015a). Desse modo, o posicionamento de um percentual de estudantes em determinado nível da escala, pressupõe-se que, além de terem desenvolvido as habilidades referentes a esse nível, provavelmente também desenvolveram as habilidades referentes aos níveis anteriores.

Nos quadros que seguem sistematizados, registram-se a distribuição percentual dos estudantes do $3^{\circ}$ ano do Ensino Fundamental de Mato Grosso por nível da Escala. O nível 1 apresenta-se como o nível mais elementar e o último nível como o mais elevado da escala 5 . Entretanto, nossa compreensão é de que, para além dos referidos níveis de aprendizagem estabelecidos pelo Inep/ANA, o processo de alfabetização precisa ser compreendido como aprendizagem da Língua Portuguesa, indissociável dos múltiplos letramentos.

\section{Análise da proficiência em leitura no ciclo da alfabetização em Mato Grosso}

Neste item, articulamos os quatro níveis definidos pelo Inep/ANA como proficiência em leitura (BRASIL, 2015a), às avaliações correspondentes a mesma proficiência, dentre os onze direitos de aprendizagem de Língua Portuguesa alocados por agrupados no SIMEC/SisPacto pelos alfabetizadores que participaram da formação ofertada pelo PNAIC no ano de 2014. Assim, estabelecemos uma análise por equivalências e destacamos alguns contrapontos. Dentre os contrapontos característicos das avaliações em larga escala, destacamos que, ao se referir a ANA, Mortatti (2013) afirma que esta avaliação primou pelo método sintético, ou seja, as questões aplicadas aos alfabetizandos no último ano do ciclo da alfabetização foram pontuais, desarticuladas de um texto e de um contexto, com exercícios que contradiziam o processo de alfabetização analítico na perspectiva dos múltiplos letramentos trabalhados na formação ofertada aos alfabetizadores pela via do PNAIC.

De acordo com a escala de proficiência de leitura, descrita no painel Educacional Estadual/Ensino Fundamental - Anos Iniciais de Mato Grosso, na aba “aprendizagem”, o nível 1 (até 450 pontos), avaliou a capacidade das crianças matriculadas no $3^{\circ}$ ano do ciclo da alfabetização de "ler palavras dissílabas, trissílabas e polissílabas com estruturas silábicas canônicas, com base em imagem” (BRASIL, 2015a, p. 26). Este nível, em nossa compreensão, articulou-se ao direito de aprendizagem alocado no agrupador 7 do

${ }^{5}$ Em Língua Portuguesa o Inep/ANA definiu 4 níveis de proficiência para a leitura e 5 níveis para a escrita. Em matemática foram 4 os níveis definidos. Portanto, em leitura e matemática o nível mais elevado foi o 4 , em escrita o maior nível de proficiência definido foi o 5 (BRASIL, 2015a). 
SIMEC/SisPacto, assim disposto: "lê palavras formadas por diferentes estruturas silábicas" (BRASIL, 2015b).

Quadro 5 - Percentual de estudantes de Mato Grosso que estavam no nível 1 de Leitura publicados pela ANA e pelo SIMEC/SisPacto no final do $3^{\circ}$ ano do ciclo da alfabetização

\begin{tabular}{|l|l|l|l|}
\hline Escolas de Mato Grosso & Nível & 2013 & 2014 \\
\hline ANA/2014* & 01 & $21,20 \%$ & $17,51 \%$ \\
\hline SIMEC/SisPacto/2014** & Agrupador 7 & - & $87,25 \%$ \\
\hline
\end{tabular}

Fonte*: Brasil/Inep/ANA (2015a).

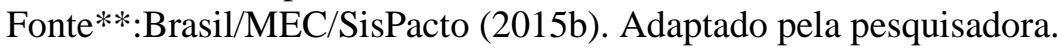

Como lemos no quadro 5, o percentual de crianças que liam "palavras formadas por diferentes estruturas silábicas", de acordo com os resultados das avaliações do SIMEC/SisPacto era de 87,75\%. No entanto, os resultados editados no Inep/ANA/2014, informaram que $17,51 \%$ dos alfabetizandos do $3^{\circ}$ ano estavam com este direito consolidado, no final do ano. Esta realidade nos remete ao debate da exclusão educacional, que a nosso ver, continua presente no processo de escolarização pública. Parece que a alfabetização ofertada, apesar da legal democratização, ainda atende apenas uma parcela da população e continua a promover a exclusão da maioria. Diante deste quadro, amparadas nas afirmações do MEC, problematizamos que a escola inclusiva seria aquela "que conhece cada aluno, respeita suas potencialidades e necessidades, e a elas responde, com qualidade pedagógica" (BRASIL, 2004, p. 8).

Em nossa compreensão, o termo qualidade pedagógica, pode estar relacionado à capacidade didática das escolas refletirem sobre a sua realidade cotidianamente, em prol da aprendizagem dos educandos. No entanto, vale a pena investigar em quais condições as escolas públicas de Mato Grosso trabalham? Quais as reais possibilidades dessas escolas promoverem estratégias que permitam conhecer cada um dos seus alunos matriculados e trabalhar com esses, ações pedagógicas que valorizem as potencialidades e as necessidades de todos? Será que os fundamentos que estruturam uma escola pública inclusiva são utópicos? Em que medida as políticas públicas educacionais podem de fato assegurar as mudanças desejáveis pelos seus formuladores/idealizadores?

O nível 2 de leitura (maior de 425 e menor 525) indicava que as crianças venceram o nível 1 e deveriam ser capazes de:

Localizar informações explícitas em textos curtos como piada, parlenda, poema, quadrinho, fragmentos de narrativas e de curiosidade científica; em textos de maior extensão, quando a informação está localizada na primeira linha do texto. Reconhecer a finalidade de texto como convite, cartaz, 
receita, bilhete, anúncio com ou sem apoio de imagem. Identificar assunto de um cartaz apresentado em sua forma original e ainda em textos cujo assunto pode ser identificado no título ou na primeira linha. Inferir sentido em piada e em história em quadrinhos que articula linguagem verbal e não verbal (BRASIL, 2015a, p. 26).

Inferimos que este nível de proficiência correspondia aos agrupadores 8 "lê textos de gêneros e temáticas familiares em voz alta" e 9 "Compreende textos, temáticas e vocabulários familiares" de Língua Portuguesa alocados no SIMEC/SisPacto. O quadro 6 informou o percentual de estudantes de Mato Grosso com as referidas proficiências consolidadas.

Quadro 6 - Percentual de estudantes de Mato Grosso que estavam no nível 2 de Leitura publicados pela ANA e pelo SIMEC/SisPacto no final do $3^{\circ}$ ano do ciclo da alfabetização

\begin{tabular}{|l|l|l|l|}
\hline Escolas de Mato Grosso & Nível & 2013 & 2014 \\
\hline ANA/2014* & 02 & $35,69 \%$ & $35,80 \%$ \\
\hline SIMEC/SisPacto/2014** & agrupadores 8 e 9 & - & $77,30 \%$ \\
\hline
\end{tabular}

Fonte*: Brasil/Inep/ANA (2015).

Fonte $^{* *}:$ Brasil/MEC/SIMEC/Sispacto (2015b). Adaptado pela pesquisadora.

Os resultados da ANA de 2014 disponibilizados pelo Inep/ANA em 2015mostraram uma realidade divergente da publicada no SIMEC/SisPacto no final de 2014. Se por um lado, o Inep/ANA informou que $35,80 \%$ das crianças estavam nesse nível de leitura, por outro, o SIMEC/SisPacto indicou que 77,30\% das crianças tinham consolidado tais habilidades. Compreendemos que em um processo de alfabetização inclusiva, é preciso lutar pelo direito de todas as crianças se apropriarem do Sistema de Escrita Alfabética (SEA). Esta apropriação inclui a compreensão de textos, temáticas e vocabulários familiares. Por isso, reeditamos as afirmações de Moreira e Candau (2007) de que é preciso recuperar o direito do educando a aprendizagem. Contudo, reconhecemos que a recuperação desse direito não se limite apenas ao trabalho do professor e sim a um conjunto de estratégias pensadas diariamente e incansavelmente por toda a comunidade escolar, articulados à contrapartida das instâncias governamentais que precisam assegurar condições de trabalho e de formação continuada a todos os profissionais da educação.

O nível 3 de leitura (maior que 525 e menos que 625 pontos), orientava que as crianças que superaram os níveis 1 e 2 deveriam ser capazes de:

Localizar informação explícita em textos de maior extensão como fragmento de literatura infantil, lenda, cantiga folclórica e poema, quando a informação está localizada no meio ou ao final do texto. Identificar o referente de um pronome pessoal do caso reto em textos como tirinha e poema narrativo. Inferir relação de causa e consequência em textos exclusivamente verbais - 
piada, fábula, fragmentos de textos de literatura infantil e texto de curiosidade científica - com base na progressão textual; e em textos que articulam a linguagem verbal e não verbal - tirinha; sentido em história em quadrinhos que articula linguagem verbal e não verbal com vocabulário específico de textos de divulgação científica ou que exige conhecimento intertextual de narrativas infantis; o assunto de texto de extensão média de divulgação científica para crianças, com base nos elementos que aparecem no início do texto; o significado de expressão de linguagem figurada em textos como poema narrativo, fragmentos de literatura infantil, de curiosidade científica e tirinha (BRASIL, 2015a, p. 26).

Analisamos os direitos de aprendizagem alocados no SIMEC/SisPacto para a inserção dos resultados das avaliações realizadas e inseridas neste Sistema pelos professores alfabetizadores, e inferimos que o agrupador que mais se aproximou das proficiências elencadas no nível 3 da ANA seria o 11 "Participa de situações produzindo e compreendendo textos orais de gêneros e temas familiares" (BRASIL, 2015b).

O quadro 7 traz o percentual de crianças que demostraram, por meio da ANA e dos resultados inseridos no SIMEC/SisPacto, que estavam com esse nível consolidado.

Quadro 7 - Percentual de estudantes de Mato Grosso que estavam no nível 3 de Leitura publicados pela ANA e pelo SIMEC/SisPacto no final do $3^{\circ}$ ano do ciclo da alfabetização

\begin{tabular}{|l|l|l|l|}
\hline Escolas de Mato Grosso & Nível & 2013 & 2014 \\
\hline ANA/2014* & 03 & $35,08 \%$ & $35,80 \%$ \\
\hline SIMEC/SisPacto/2014** & agrupador/direito 11 & - & $83,20 \%$ \\
\hline
\end{tabular}

Fonte*: Brasil/Inep/ANA (2015).

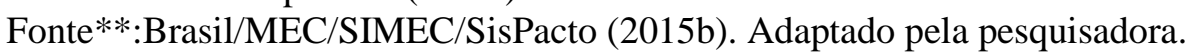

Em proficiências equivalentes a essa, as avaliações realizadas pelos alfabetizadores de Mato Grosso informaram que aproximadamente $17 \%$ das crianças matriculadas no Ciclo da Alfabetização, ao final de 2014 ainda não tinham consolidado esse direito. Tomando-se por base a equivalência realizada nesse nível, o percentual informado pelo SIMEC/SisPacto representa mais que o dobro do editado pela ANA. Contudo, observamos coerência nos resultados divulgados pela ANA, uma vez que o percentual de estudantes que ainda não dominavam os níveis de aprendizagem divulgados pelo Inep/ANA apresentava regularidades em relação a esses níveis. Para que as crianças possam participar de situações com produção e compreensão de textos orais de gêneros e temas familiares, elas precisam primeiro, compreender textos, temáticas e vocabulários familiares. O percentual de crianças que não tinham construídas estas habilidades ao final do $3^{\circ}$ ano, também estava em torno de $35 \%$.

A clareza processual da apropriação do SEA justificou a ampliação da alfabetização para três anos sem retenção. Todavia, "nesse contexto, a construção/apropriação do 
conhecimento pelos estudantes se daria em uma progressão durante o período. Tal opção, contudo, não implica deixar de garantir os direitos de aprendizagem necessários a cada ano" (CRUZ, 2012, p. 08). Os dados resultantes da realização da ANA indicaram que os referidos direitos não estavam sendo devidamente apropriados pelos alfabetizandos em cada ano do ciclo. Esta situação chamou a atenção e sinalizou a necessidade de estudos aprofundados voltados ao tema em questão. Esses estudos poderão elucidar que as instâncias governamentais precisam repensar a educação e suas respectivas políticas por outros ângulos. Deixar de culpabilizar os implementadores dessas políticas e analisar as condições em que se dão suas implementações seria a nosso ver, uma decisão importante.

O nível 4 de leitura (maior que 625 pontos) compreende que as crianças que consolidaram os níveis anteriores deverão ser capazes de:

Reconhecer relação de tempo em texto verbal e os participantes de um diálogo em uma entrevista ficcional. Identificar o referente de pronome possessivo em poema; o referente de advérbio de lugar em reportagem; o referente de expressão formada por pronome demonstrativo em fragmento de texto de divulgação científica para o público infantil. Inferir sentido em fragmento de conto; sentido de palavra em fragmento de texto de literatura infantil; assunto em texto de extensão média ou longa, considerando elementos que aparecem ao longo do texto, em gêneros como divulgação científica, curiosidade histórica para criança e biografia (BRASIL, 2015a, p. 26).

O percentual relativo a esta proficiência encontra-se sistematizado no quadro seguinte:

Quadro 8 -: Percentual de estudantes de Mato Grosso que estavam no nível 4 de Leitura publicados pela ANA e pelo SIMEC/SisPacto no final do $3^{\circ}$ ano do ciclo da alfabetização

\begin{tabular}{|l|l|l|l|}
\hline Escolas de Mato Grosso & Nível & 2013 & 2014 \\
\hline ANA/2014* & 04 & $8,05 \%$ & $10,94 \%$ \\
\hline SIMEC/SisPacto/2014** & agrupador 11 & - & $83,20 \%$ \\
\hline
\end{tabular}

Fonte*: Brasil/Inep/ANA (2015a).

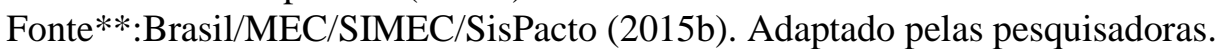

Assim como no nível 3, em nossa análise por equivalência, o agrupador de aprendizagem alocado no SIMEC/SisPacto que mais se aproximou das proficiências destacadas no nível 4 de leitura da ANA seria o 11 "Participa de situações produzindo e

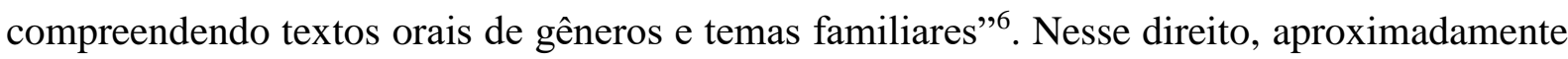
17\% dos alfabetizandos matriculados no Ciclo da Alfabetização, segundo o resultado das

${ }^{6}$ Nessa pesquisa associamos/articulamos os onze direitos de aprendizagem alocados no SIMEC/SisPacto por agrupadores, aos quatro níveis de proficiência em leitura e aos cinco níveis de proficiência em escrita. Esse exercício foi complexo e as equivalências estabelecidas em alguns níveis, articularam-se aos mesmos agrupadores, pelo menos em nossa compreensão.

RPGE- Revista on line de Política e Gestão Educacional, Araraquara, v. 22, n. 3, p. 1047-1064, set./dez., 2018. E-ISSN:1519-9029. DOI: 10.22633/rpge.v22i3.11419 
avaliações do SIMEC/SisPacto, não os tinha consolidado. Em contrapartida, os resultados editados pela ANA, correspondentes ao mesmo ano, informaram que em média $11 \%$ dos alfabetizandos estavam com este nível de aprendizagem consolidado no final do $3^{\circ}$ ano.

Esses indicadores denunciam que o fato de o sistema excluir a reprovação no Ciclo da Alfabetização, não se traduz na inclusão do alfabetizando ao processo educacional. Esses percentuais demandam estudos mais aprofundados e análises cuidadosas, mesmo porque compreendemos ser este o sentido dessas avaliações. Uma análise dos indicadores sociais poderá auxiliar na compreensão dos motivos pelos quais tantas crianças não atingiram a fase alfabética no $2^{\circ}$ ano do ciclo e não conseguiram "avançar com autonomia na consolidação da capacidade de leitura de textos para que se tornarem progressivamente alfabetizadas e letradas" (CRUZ, 2012, p. 21).

Contudo, inferimos que podem ter faltado intervenções docentes com proposições de práticas pedagógicas que poderiam ajudar a criança a desenvolver "uma leitura fluente e compreensão dos textos lidos com autonomia" (CRUZ, 2012, p. 21). Como também, podem ter faltado intervenções com estratégias de leitura e de oralidade voltadas para a exploração da diversidade de gêneros textuais que circulam no meio social, articuladas as atividades indicadas para o desenvolvimento da consciência fonológica dos alfabetizandos.

\section{Considerações finais}

Como problematizamos anteriormente, segundo Mortatti (2013), a ANA priorizou o método sintético de alfabetização em sua formulação, enquanto que a formação ofertada pelo PNAIC aos alfabetizadores investiu em um trabalho pedagógico com o objetivo de "expandir as capacidades relativas ao letramento, que envolveu a compreensão e o uso de textos variados, com estrutura mais complexa, com temas diversificados, e que circulem em diferentes esferas sociais" (MORTATTI, 2013, p. 28). Em atenção a esse objetivo, o professor alfabetizador tentou fazer o seu trabalho preocupado com os aspectos que seriam cobrados na ANA com o que o PNAIC orientava. Essa conjuntura pode ter influenciado nos resultados publicizados por esses dois sistemas avaliativos.

Os resultados das avaliações analisados em todos os níveis de leitura definidos pela ANA indicaram que o percentual de crianças que concluíram o ciclo da alfabetização sem consolidar os respectivos direitos de aprendizagem é preocupante. Assim como a discrepância dos resultados dispostos no SIMEC/SisPacto de 72,26\% para mais em relação aos resultados publicados no Inep/ANA no nível 4. Como afirmamos atingir esse nível seria condição para 
que o estudante pudesse avançar sem prejuízos no seu processo de escolarização básica. Condição que apenas 10,94\% dos alfabetizandos de Mato Grosso atingiram ao concluírem o ciclo, segundo o Inep/ANA/2014 (BRASIL, 2015a). Esse percentual respondeu ao nosso questionamento. Os dados das avaliações realizadas pelos alfabetizadores inseridos no SIMEC/SisPacto em 2014 não corresponderam aos resultados decorrentes da realização da ANA nesse mesmo ano, divulgados pelo Inep/ANA das respectivas turmas (BRASIL, 2015a).

Diante desse quadro, outra problematização que julgamos relevante apontar nessas considerações voltou-se aos pressupostos ideológicos, culturais e políticos que moveram as avaliações internas e externas. Como os professores alfabetizadores compreenderam as avaliações escolares? Qual concepção avaliativa sustentou o processo interventivo/avaliativo dos professores? Eles tinham claro que ao publicarem as avaliações das suas turmas, divulgariam o resultado dos seus trabalhos. Este seria um dado interessante a ser estudado e analisado. Mesmo cientes de todos os percalços que interferem na aprendizagem dos estudantes, os professores assumiram essa responsabilidade e temeram sofrer punições, por isso a discrepância entre as equivalências estabelecidas nos resultados dos sistemas analisados? E em relação à ANA, em quais condições e contextos a sua edição foi formulada e aplicada?

Os números publicados por essas avaliações, especificamente pela ANA, indicaram que há, ainda, muito que se fazer para que as crianças desse estado tenham os direitos de aprendizagem em leitura no ciclo da alfabetização, assegurados. Alfabetizar na perspectiva do letramento, ou dos múltiplos letramentos, supera a adoção do método sintético e do discurso de que as crianças precisam "aprender a aprender". Como afirmou Mortatti (2013, p. 29), são muitos os "aspectos que continuam intocados na caixa preta da alfabetização escolar no Brasil”. Esses aspectos indicam, dentre outras coisas, que as metodologias e as estratégias avaliativas adotadas, tanto nas avaliações internas, como nas avaliações externas, precisam ser profundamente estudadas, analisadas e repensadas pelas suas respectivas instâncias para que as metas e os fins estabelecidos para elas sejam alcançados.

Em nossa compreensão, os professores alfabetizadores, na condição de agentes letradores, são protagonistas importantes a considerar nos percursos de formulação de políticas públicas educacionais, principalmente quando o desafio perpassa pelo (re)pensar da função social da escola enquanto agência de letramentos e dos profissionais docentes como aqueles que fazem a mediação pedagógica dos eventos e práticas de leitura e escrita sob o viés dos múltiplos letramentos enquanto práticas sociais. 
AGRADECIMENTOS: Coordenadoria de Aperfeiçoamento de Pessoal de Nível Superior (CAPES), Programa Nacional de Pós-Doutorado (PNPD).

\section{REFERÊNCIAS}

BRASIL. Ministério de Educação. Secretaria de Educação Básica. Educação inclusiva: a escola. V.3. Brasília, 2004.

BRASIL. Ministério da Educação. Secretaria de Educação Básica. Diretoria de Apoio a Gestão Educacional. Pacto Nacional Pela Alfabetização na Idade Certa. Avaliação no Ciclo da Alfabetização: reflexões e sugestões. Brasília: 2012.

BRASIL. Instituto Nacional de Estudos e Pesquisas Educacionais Anísio Teixeira. Avaliação Nacional da Alfabetização: relatório 2013-2014: volume 2: análise dos resultados. Brasília, DF: Inep, 2015a.

BRASIL. Ministério da Educação. SIMEC/SisPacto, 2014. Disponível em: SiMEC.gov.MEC.br/sispacto2/sispacto2.php?modulo=relatorio/relatoriospersonalizados\&aca o=. Acesso em: 10 abr. $2015 b$.

CARDOSO, Cancionila Janzkovski; CARDOSO, André Luiz Janzkovski. Formação continuada no contexto do Pacto Nacional pela Alfabetização na Idade Certa: alinhamento entre práticas, princípios formativos e Objetivos. Práxis Educativa, Ponta Grossa, v. 11, n. 1, p. 89-106, jan./abr. 2016. Disponível em: http://www.revistas2.uepg.br/index.

php/praxiseducativa. Acesso em: 20 abr. 2016.

CRUZ, Magna do Carmo Silva. Currículo no ciclo de alfabetização: ampliando o direito de aprendizagem a todas as crianças. In.: BRASIL, Secretaria de Educação Básica. Diretoria de Apoio à Gestão Educacional. Pacto Nacional pela Alfabetização na Idade Certa: Currículo na Alfabetização: consolidação e monitoramento do processo de aprendizagem. Ano 02, Unidade 01. Brasília: MEC, SEB, 2012.

MARCONI, Marina de Andrade.; LAKATOS, Eva Maria. Técnicas de Pesquisa: planejamento e execução de pesquisas, amostragens e técnicas de pesquisas, elaboração, análise e interpretação de dados. 5. ed. São Paulo: Atlas, 2002.

MOREIRA, Flávio Barbosa.; CANDAU, Vera Maria. Currículo, conhecimento e cultura. In: BRASIL, Ministério da Educação, Secretaria de Educação Básica. Indagações sobre currículo. (Orgs.) BEAUCHAMP, Janete et al. Brasília, 2007. Disponível em: http://portal. MEC.gov.br/seb/ arquivos/pdf/Ensfund/indag3.pdf. Acesso em: 10 abr. 2016.

MORTATTI, Maria do Rosário Longo. Um balanço crítico da "década da alfabetização" no Brasil. Cad. Cedes, Campinas, v. 33, n. 89, p. 15-34, jan.-abr. 2013. Disponível em: http://www.cedes.unicamp.br. Acesso em: 10 mar. 2016.

ROJO, Roxane. Gêneros discursivos do círculo de Bakhtin e multiletramentos. In: ROJO, Roxane (Org.). Escolas conectadas: os multiletramentos e as TICs. São Paulo: Parábola Editora, 2013. p. 13-36. 


\section{Como referenciar este artigo}

MELLO, Ângela Rita Christofolo de. A proficiência em leitura no ciclo da alfabetização em Mato Grosso. Revista on line de Política e Gestão Educacional, Araraquara, v. 22, n. 3, p. 1047-1064, set./dez., 2018. E-ISSN:1519-9029. DOI: 10.22633/rpge.v22i3.11419

Submetido em: $31 / 05 / 2018$

Aprovado em: 10/08/2018 